\title{
Solar irradiance uncertainty management based on Monte Carlo-beta probability density function: case in Malaysian tropical climate
}

N. Md. Saad, M. Z. Sujod, M. I. M. Ridzuan, M. F. Abas, M. S. Jadin, M. S. Bakar, A. Z. Ahmad

Sustainable Energy \& Power Electronics Research Laboratory, Faculty of Electrical and Electronics Engineering, Universiti Malaysia Pahang, Malaysia

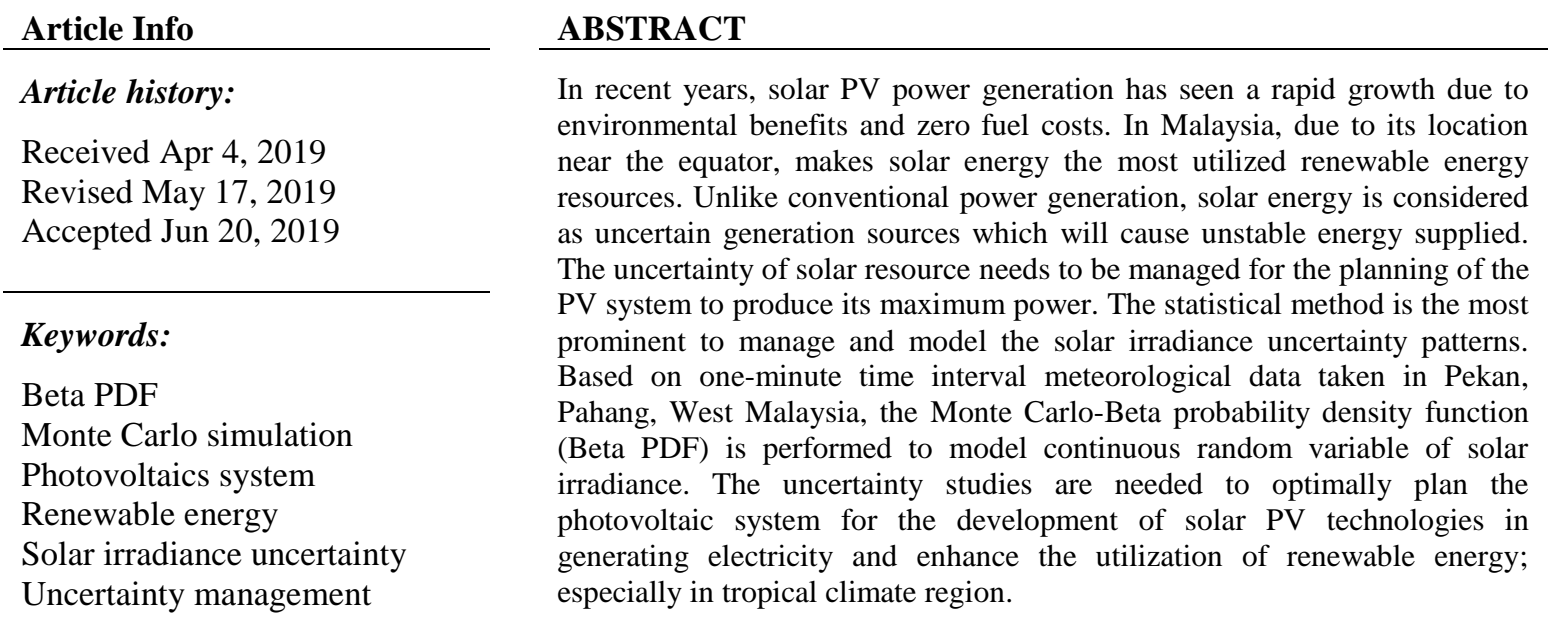

Copyright $@ 2019$ Institute of Advanced Engineering and Science. All rights reserved.

\section{Corresponding Author:}

N. Md. Saad,

Faculty of Electrical and Electronics Engineering,

Universiti Malaysia Pahang,

26600, Pekan, Pahang, Malaysia.

Email: norhafidzah@ump.edu.my

\section{INTRODUCTION}

Malaysia is comprising of the Peninsular Malaysia; which known as West Malaysia and the state of Sabah and Sarawak; known as East Malaysia. Malaysia is located on South China Sea between $1^{\circ}$ and $7^{\circ}$ in North latitude and $100^{\circ}$ and $120^{\circ}$ in East longitude on the equatorial zone which being hot and humid throughout the year. Hence, solar energy is abundance and can be harnessed all year round. Solar energy has become the most popular renewable energy resources in Malaysia due to its availability, an environmentally friendly to generate electricity [1-4]. The grid maps of annual solar irradiation for Peninsular (West Malaysia) and state of Sabah and Sarawak (East Malaysia) are depicted in Figure 1 and Figure 2 respectively [5].

The ambient temperature in Malaysia ranges between $22^{\circ} \mathrm{C}$ to $33^{\circ} \mathrm{C}$ with average of daily temperature measured at approximately $26.5^{\circ} \mathrm{C}$ [2]. With elevated level of temperature and humidity, the annual average daily solar irradiations for Malaysia is measured between the ranged of $4.21 \mathrm{kWh} / \mathrm{m}^{2}$ to 5.56 $\mathrm{kWh} / \mathrm{m}^{2}$ [6]. The average of solar irradiation in Malaysia per year is approximately $1643 \mathrm{kWh} / \mathrm{m}^{2}$ [7]. Since the solar radiation is not applicable at night, the solar energy could be harvest from 8 am to 7 pm throughout the year [8]. The map of Malaysia on the equatorial zone which being hot and humid, is an advantage for the country in moving towards solar energy sources to reduce dependency in fossil oil [9]. The tropical climate 
condition in Malaysia makes it possible for the development of solar PV technologies to generate electricity and enhance the utilization of RES for sustainable development in national electricity supply [7, 10].

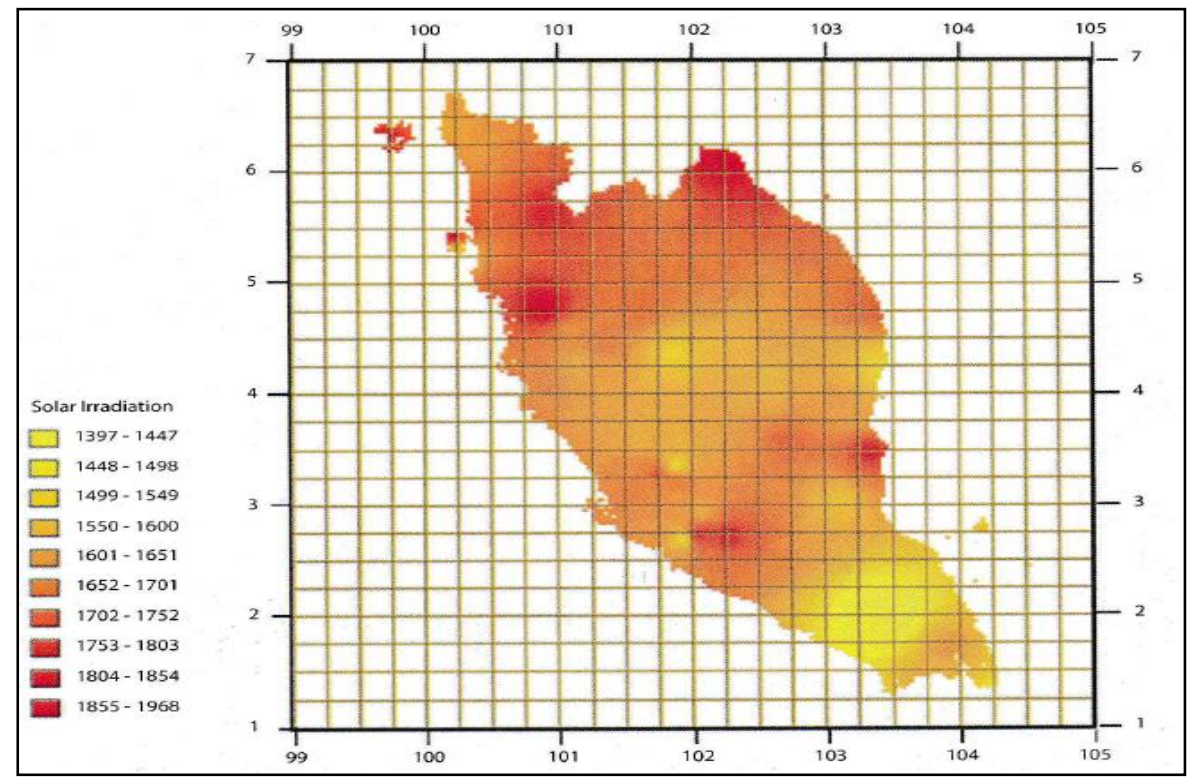

Figure 1. Grid map of peninsular Malaysia (West Malaysia)

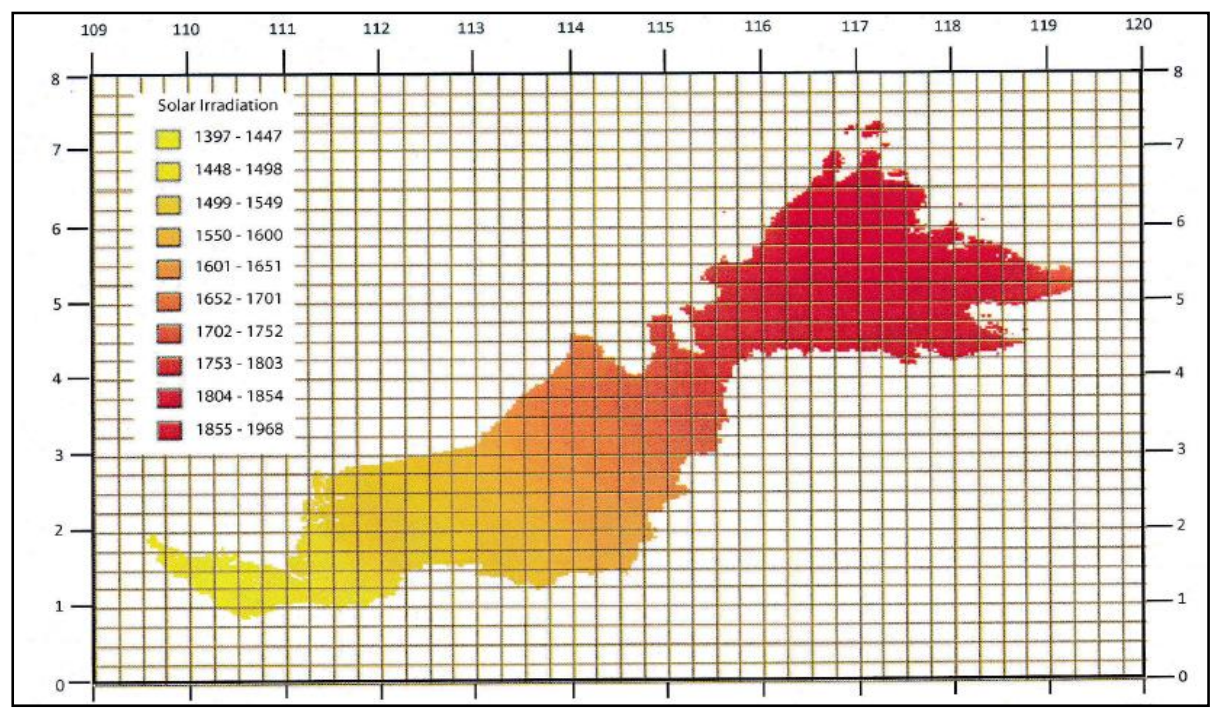

Figure 2. Grid map of East Malaysia (Sabah and Sarawak)

However, solar radiation in tropical climate has a high degree of uncertainty which depends on the environmental and meteorological conditions $[11,12]$. The conditions such as cloud cover, haze, fog, shadow conditions, rapid change in ambient temperature and irradiance will contribute to solar radiation uncertainty, which will cause the energy supplied by photovoltaic systems become unstable and cause negative impacts on the utility grid stability $[13,14]$. To optimally plan and integrate PVs in grid connected system, the modelling, control and optimization studies of power system considering uncertainties are needed [3, 15-20]. Thus, this paper will explore the solar irradiance uncertainty for case study in Pekan, Pahang, Malaysia. The paper comprises of five sections. Section 1 is introduction. Section 2 discussed on solar irradiance meteorological data. Section 3 discussed on statistical model of solar irradiance patterns based on Monte 
Carlo-Beta PDF. The results, discussions and conclusions are presented in Section 4 and Section 5 respectively.

\section{METEOROLOGICAL DATA COLLECTION}

The stochastic data preparation for uncertainty components of distributed solar generation is based on meteorological solar irradiance and ambient temperature taken at Renewable Energy laboratory, Faculty of Electrical \& Electronics, Universiti Malaysia Pahang, at GPS coordinate latitude $3^{\circ} 32^{\prime}$, longitude $103^{\circ} 26^{\prime}$. The one reference year historical data with one-minute time intervals is used to develop the data set of solar generation uncertainty as described below:

$$
\begin{gathered}
60 \text { minute } \times(24 \text { hours } / \text { day }) \times(30 \text { days } / \text { month }) \times(12 \text { month } / \text { year }) \\
=518,400 \text { minutes } / \text { year }
\end{gathered}
$$

\section{MONTE-CARLO-BETA PDF METHOD}

The solar irradiance is assumed as a random variable property; hence the behavior can be mapped to a probabilistic distribution [21]. The interpretation of this probability distribution varies with regards to the nature of variable which fall into continuous variable [22]. For modeling the uncertainty in solar radiation, the Monte Carlo-Beta PDF is employed. The flowchart of non-sequential Monte Carlo is demonstrated in Figure 3. The statistical mean, $\mu$ and standard deviation, $\sigma$, is calculated based on the historical data set as following [22, 23];

$$
\begin{aligned}
& \mu=\frac{1}{N_{d}} \sum_{j=1}^{N_{d}} d_{j} \\
& \sigma=\sqrt{\frac{1}{N_{d}} \sum_{j=1}^{N_{d}}\left(d_{j}-\mu\right)^{2}}
\end{aligned}
$$
$[24,25]$

The probabilistic distribution of solar irradiance is based on Beta PDF, as expressed in (3) to (6)

$$
\begin{aligned}
& f(s)= \begin{cases}\frac{\Gamma(\alpha+\beta)}{\Gamma(\alpha) \Gamma(\beta)} \cdot s^{(\alpha-1)} \cdot(1-s)^{(\beta-1)}, \text { for } 0 \leq s \leq 1, \alpha \geq 0, \beta \geq 0 \\
0 & \text {, otherwise }\end{cases} \\
& \beta=(1-\mu) \cdot\left(\frac{\mu(1+\mu)}{\sigma^{2}}-1\right) \\
& \alpha=\frac{\mu \beta}{1-\mu} \\
& P\left[S=s_{i}\right]=\int_{s_{i, \min }}^{s_{i, \max }} f(s) d s
\end{aligned}
$$

Where $\mathrm{s}$ is the solar irradiance in $\mathrm{kW} / \mathrm{m}^{2}, f(s)$ is probability density function as Beta PDF, $\alpha$ and $\beta$ are the shape parameters for the Beta PDF. The statistical model is sampled based on one-minute interval for one reference year data which is segmented into twelve months. For each month which has been segmented, there will be multiple data points for the same minutes over a month by considering data for every single day. The data sets involved in each segment for all the days over a year are divided into 288 segments (24 hours x 12 months). There are 1440 data (60 minutes x 24 hours) for each 24 segments.

The variance of the data sets is calculated to determine the maximum iterations needed for Monte Carlo simulation to perform. Based on Figure 4, the variance for solar irradiance data became stable after 3000 iterations. Thus, the Monte Carlo is performed for 3000 iterations to sample continuous random variables of the solar irradiance. Then, the average output from the simulation is calculated. 


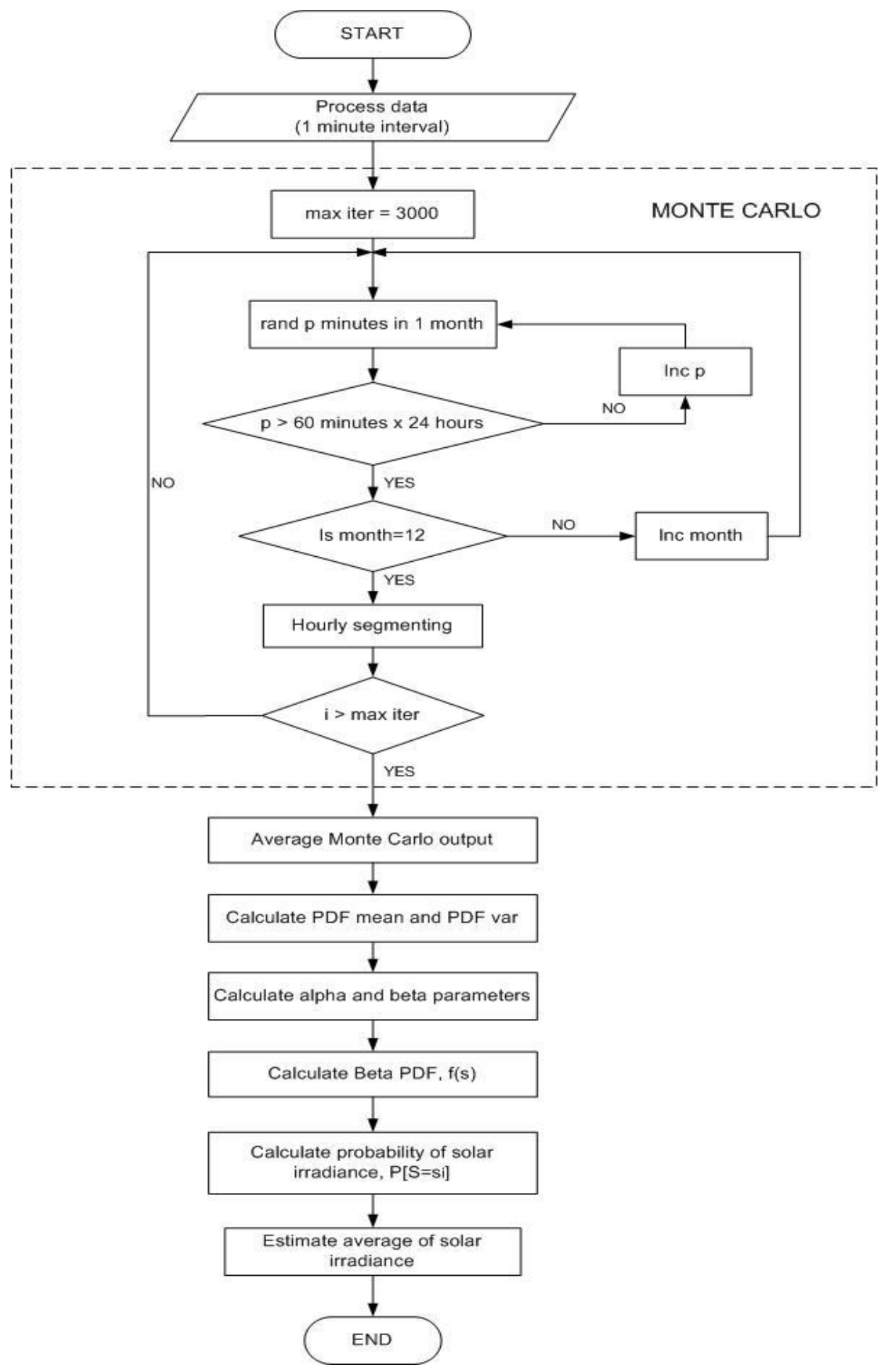

Figure 3. Flowchart of Monte Carlo-beta PDF procedures 


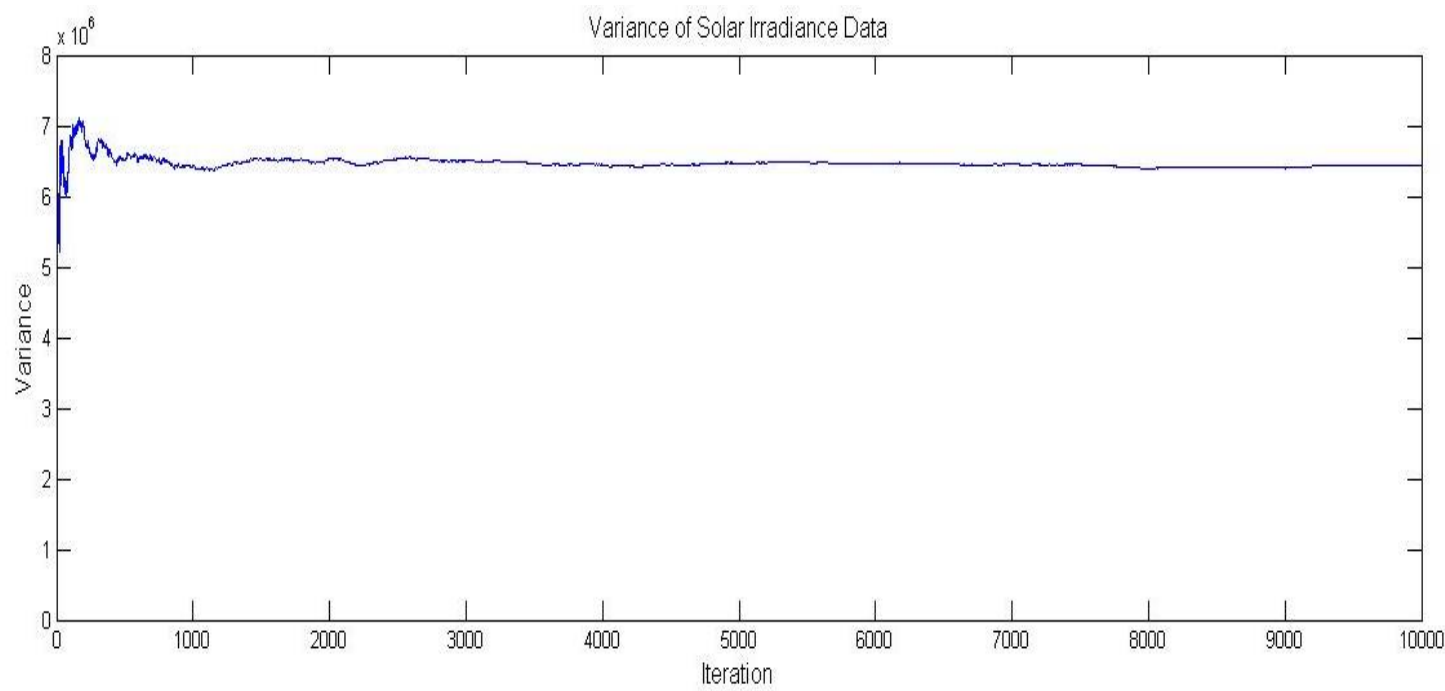

Figure 4. Variance for solar irradiance data to determine maximum iteration for Monte Carlo method

\section{RESULTS AND ANALYSIS}

\subsection{Solar irradiance pattern in Pekan, Pahang, West Malaysia}

The one-minute interval meteorological data are obtained to factorize and segmented for modeling purposes of solar irradiance uncertainty. Figure 5 demonstrates the variation in solar irradiance measurements for 1-hour sample data in Pekan, Pahang, Malaysia. It consisted of 60 data points for 1-hour sample data with 1-minute time interval which clearly show that uncertainties are apparent. The data also shows uniformly incline irradiance data which indicate that the sun is rising.

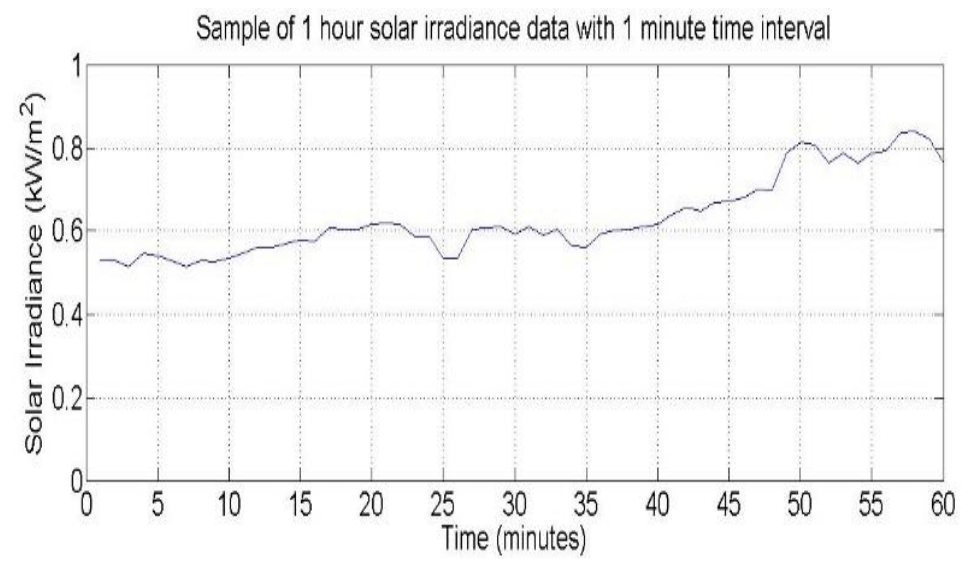

Figure 5. Sample of 1-hour solar irradiance uncertainty data with 1-minute time interval

The average hourly data of solar irradiance for one reference year were analyzed and illustrated in Figure 6. These data sets are used as baseline in the corresponding probabilistic modeling studies of solar irradiance uncertainty. The data are divided into a specified number of segments representing the Beta probability distribution patterns of time-varying solar radiation. Set of factorized curves representing the solar irradiance for 288 segments based on Monte Carlo simulation is depicted in Figure 7. The probabilistic of solar irradiance patterns for 288-time segments are depicted in Figure 8. Figure 9 shows the curve representing the average total daily solar irradiance for one typical year.

The results obtained is compared with official ground data supplied by SEDA Malaysia, for location GPS coordinate latitude $3^{\circ} 29^{\prime}$ and longitude $103^{\circ} 20^{\prime}$ for Pekan Pahang site [5]. The results of average total daily solar irradiation obtained from Renewable Energy Laboratory of UMP Pekan, and SEDA for Pekan site can be seen in Figure 10. These data are plotted for every month based for one reference year. The solar radiation data by NASA are satellite data which can be used for validity of results obtained by Renewable Energy Laboratory. 

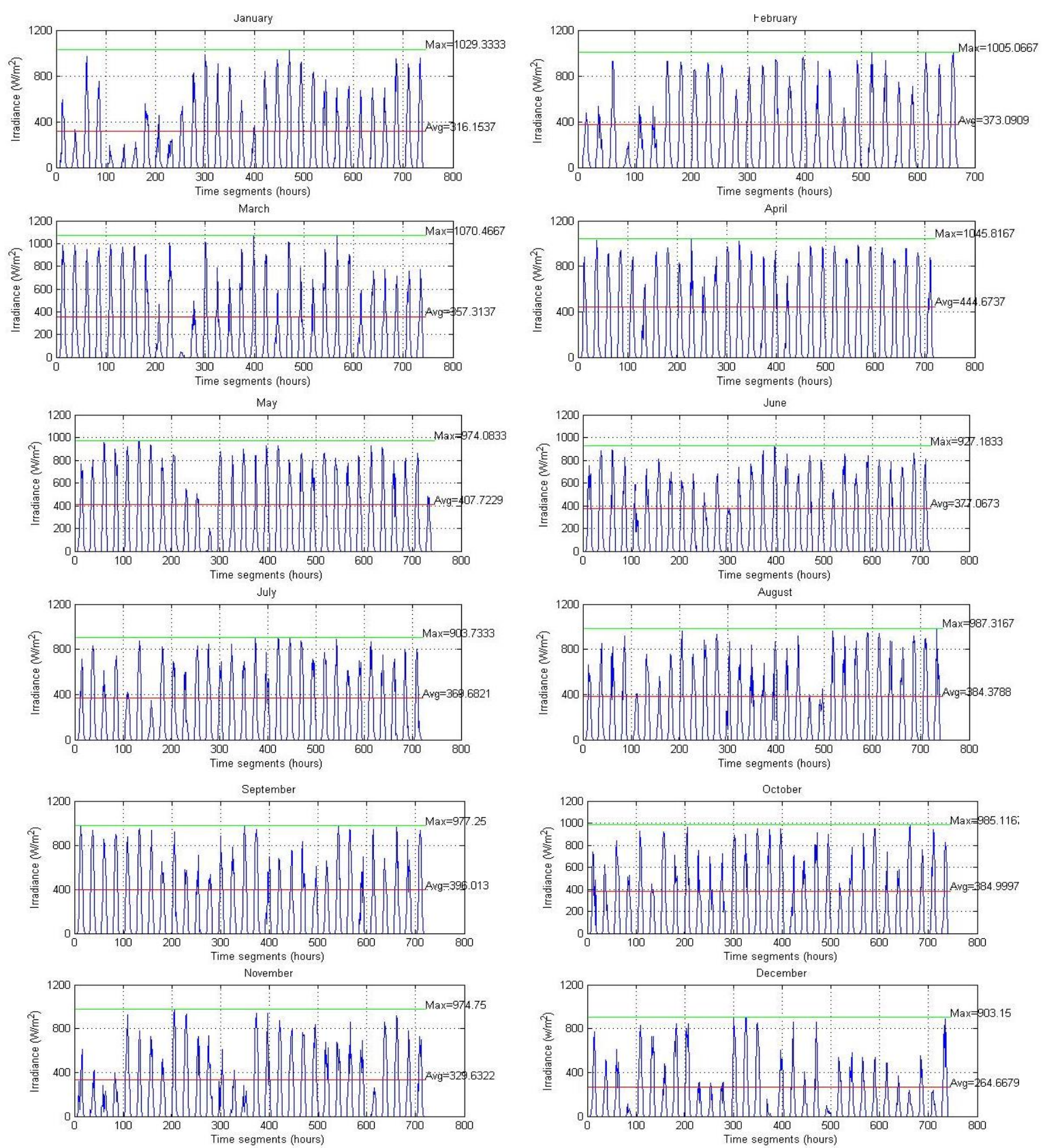

Figure 6. Average hourly data of solar irradiance for one reference year in Pekan Pahang, Malaysia

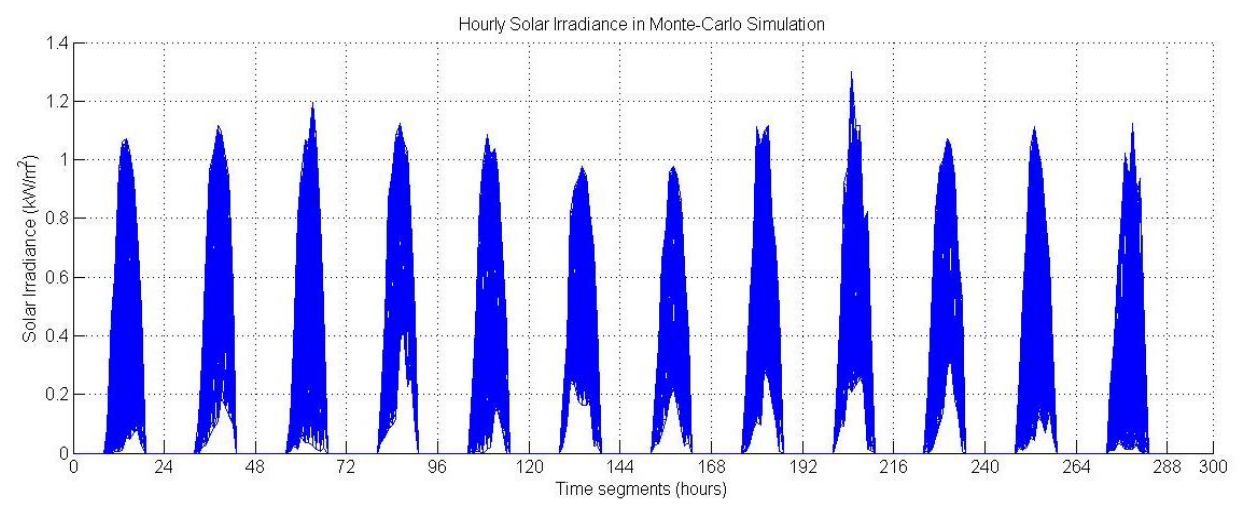

Figure 7. Solar Irradiance for 288-time segments using Monte-Carlo simulation 


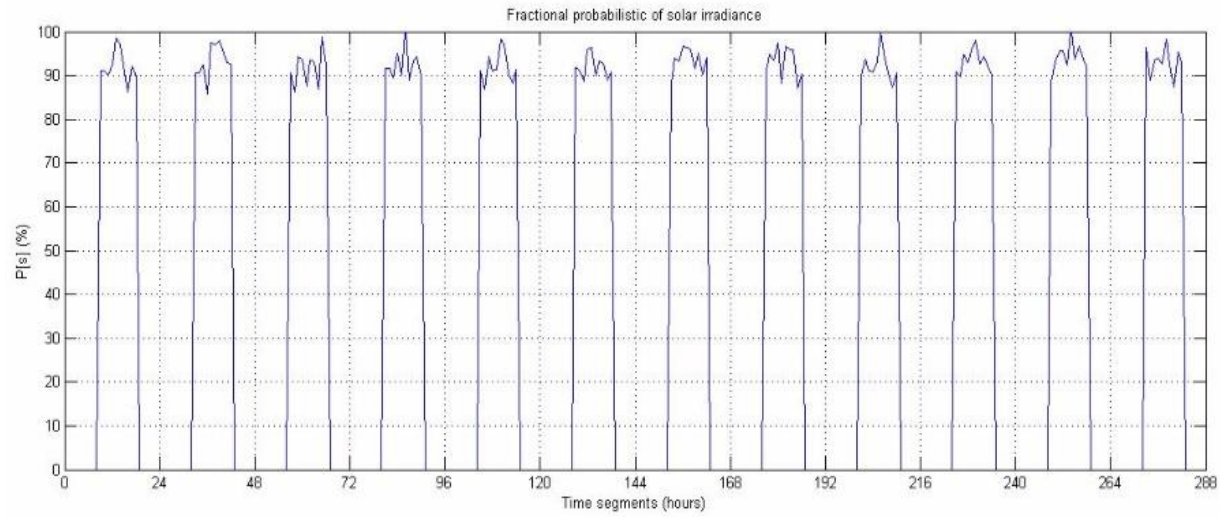

Figure 8. Fractional probabilistic of solar irradiance for 288 segments
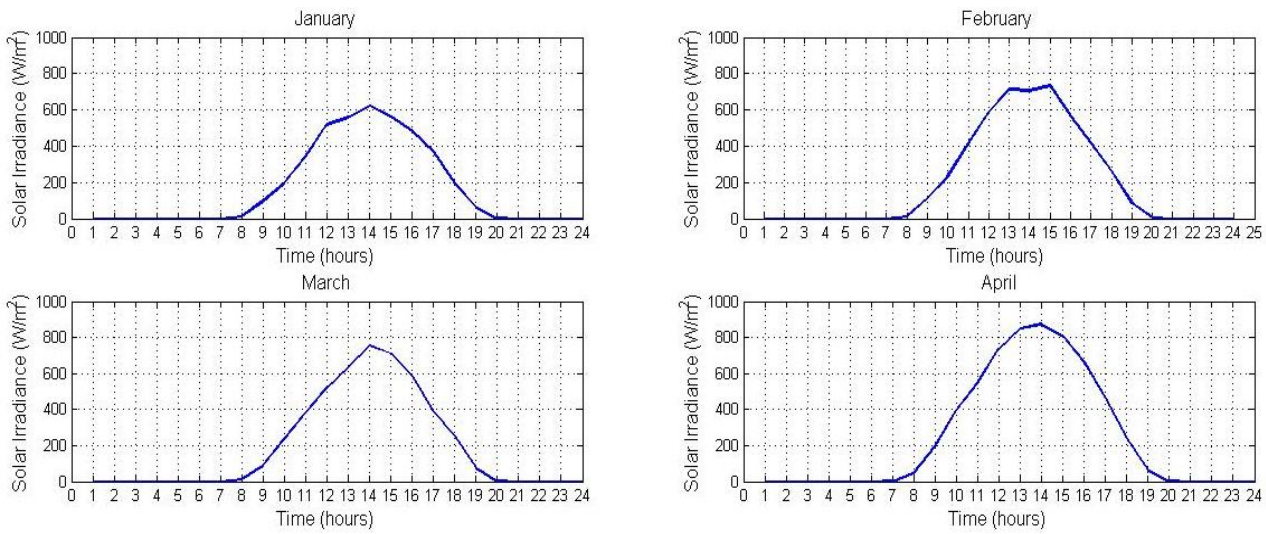

$\mathrm{Ma}$
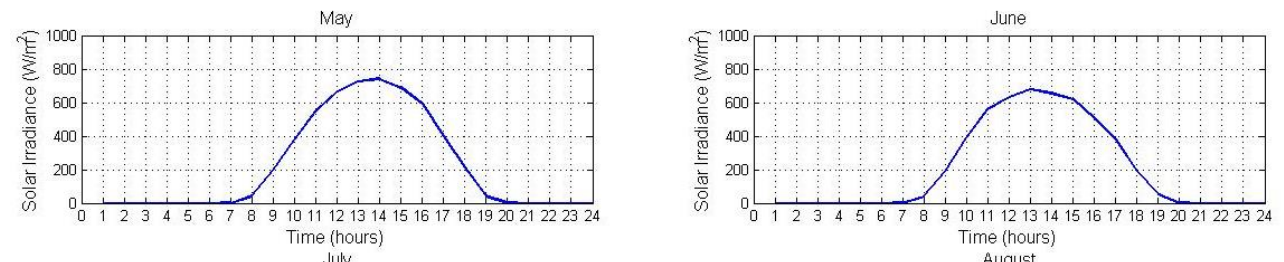

July
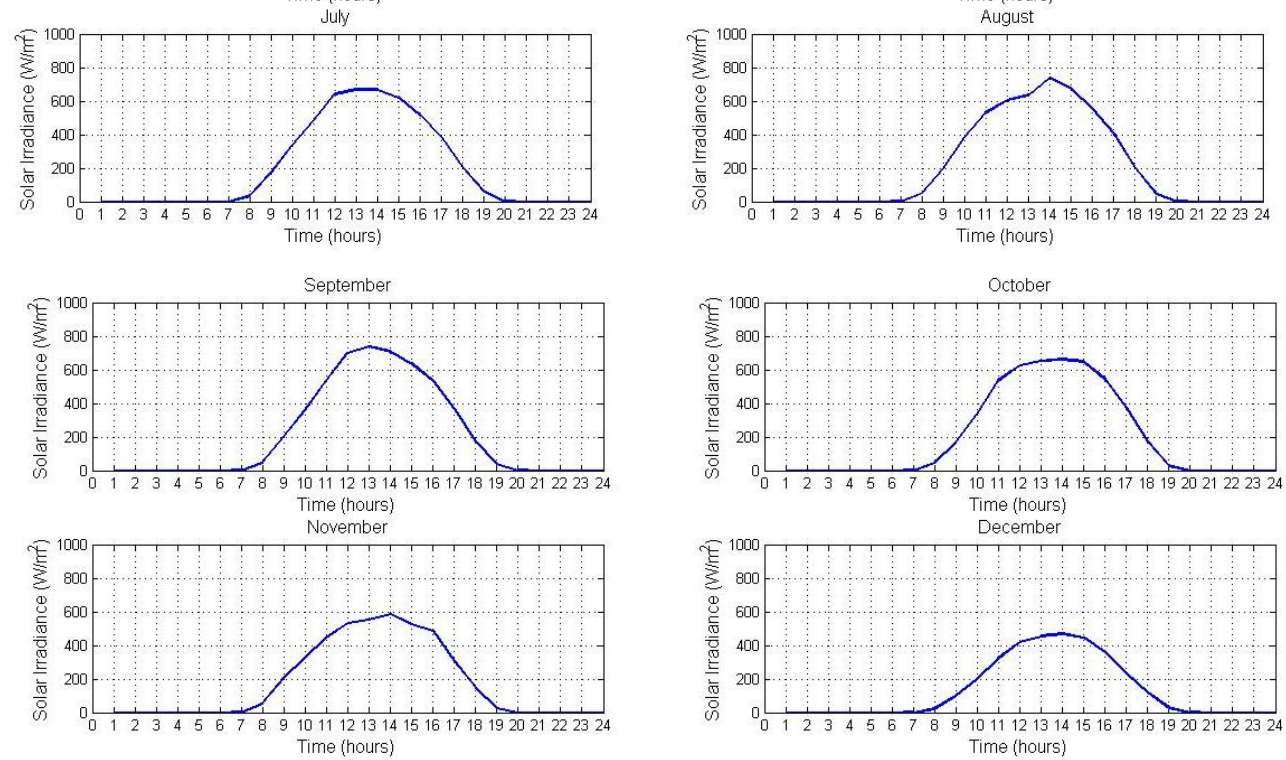

Figure 9. Average daily solar irradiance pattern 


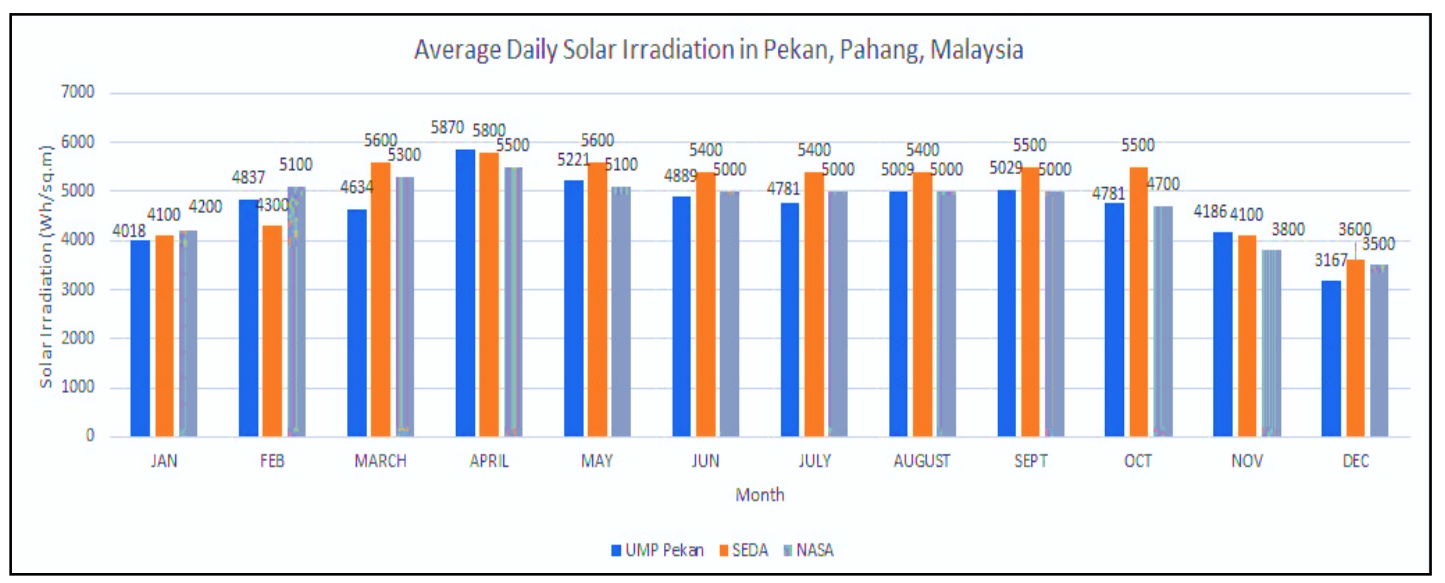

Figure 10. Average total daily solar irradiation

\subsection{Analysis of results}

The solar irradiance output peak in any typical day can be estimated to occur between the hours of 11a.m. to 4p.m. in any typical day as depicted in Figure 9. It has been observed that the highest peaks in average daily solar irradiance can be seen during April with the irradiance value of about $874 \mathrm{~W} / \mathrm{m}^{2}$. The lowest peaks of average daily solar irradiance are occurred in December with the value of $469.2 \mathrm{~W} / \mathrm{m}^{2}$, followed by November and January with the peak value of average daily solar irradiance at $584.6 \mathrm{~W} / \mathrm{m}^{2}$ and $622.3 \mathrm{~W} / \mathrm{m}^{2}$ respectively.

The average daily solar irradiances are low during November, December and January due to the Northeast Monsoon which brings in more rainfall compared to the Southwest Monsoon. The rainfall season during November to December creates greater temperature variations, large amount of cloud cover and humidity levels which produce cooler and wetter weather thus affected the solar radiation pattern. March and October which are the transitions between the two monsoons; Northeast Monsoon and Southwest Monsoon recorded the output peak of average daily solar irradiance at $755.9 \mathrm{~W} / \mathrm{m}^{2}$ and $660.7 \mathrm{~W} / \mathrm{m}^{2}$ respectively. The duration of solar resources availability can be approximated to occur between the hours of $7 \mathrm{a} . \mathrm{m}$ to $7 \mathrm{p} . \mathrm{m}$. for entire year.

In terms of solar irradiations; which is the solar irradiance integrated over time, the results of average total daily solar irradiation obtained from Renewable Energy Laboratory of UMP Pekan, indicate almost similar patterns with acceptable percentage deviation as compared to SEDA and NASA data for Pekan site as illustrated in Figure 10. The highest total average daily solar irradiation in UMP Pekan is occurred in April at $5870 \mathrm{Wh} / \mathrm{m}^{2}$. The lowest total average daily solar irradiation is occurred during rainfalls season in December with the value of $3167 \mathrm{Wh} / \mathrm{m}^{2}$, followed by January and November at $4018 \mathrm{Wh} / \mathrm{m}^{2}$ and $4186 \mathrm{Wh} / \mathrm{m}^{2}$ respectively. As depicted in Figure 10, the percentage deviation of data obtained by Renewable Energy Laboratory as compared to data released by SEDA and NASA are less than $15 \%$.

\section{CONCLUSION}

This paper has presented the necessity of managing the solar irradiance uncertainty based on tropical climate condition for utilization of solar photovoltaics technology and development in Malaysia. Since solar irradiance has uncertain output which can be classified as continuous random, it is difficult to precisely controlled and predict the output of PVDG for integration to grid system. Hence, the Monte-Carlo-Beta PDF is exploited to model the continuous random variable for uncertainty management of solar irradiance pattern in Malaysian Tropical Climate. The results show almost similar patterns with less than $15 \%$ deviation as compared to data by SEDA and NASA. For future direction, the optimization technique will be utilized to handle the randomness and stochasticity of solar PV for optimally planning and operation of PVDG integration in power system network in Malaysia.

\section{AKNOWLEDGEMENTS}

This research has been carried out in Renewable Energy laboratory, Faculty of Electrical \& Electronics, University Malaysia Pahang under Fundamental Research Grant Scheme RDU160151. 


\section{REFERENCES}

[1] S. Mekhilef, A. Safari, W. E. S. Mustaffa, R. Saidur, R. Omar, and M. A. A. Younis, "Solar energy in Malaysia : Current state and prospects," Renew. Sustain. Energy Rev., vol. 16, no. 1, pp. 386-396, 2012.

[2] S. Mekhilef, M. Barimani, A. Safari, and Z. Salam, "Malaysia's renewable energy policies and programs with green aspects," Renew. Sustain. Energy Rev., vol. 40, pp. 497-504, 2014.

[3] N. M. Saad et al., "Impacts of Photovoltaic Distributed Generation Location and Size on Distribution Power System Network," Int. J. Power Electron. Drive Syst., vol. 9, no. 2, 2018.

[4] J. Wong, Y. S. Lim, J. H. Tang, and E. Morris, "Grid-connected photovoltaic system in Malaysia: A review on voltage issues," Renew. Sustain. Energy Rev., vol. 29, pp. 535-545, 2014.

[5] SEDA Malaysia, Solar Irradiation Data For Malaysia, First edit. Malaysia: Sustainable Energy Development Authority Malaysia (SEDA), 2016.

[6] A. M. Humada, M. Hojabri, H. M. Hamada, F. B. Samsuri, and M. N. Ahmed, "Performance evaluation of two PV technologies (c-Si and CIS) for building integrated photovoltaic based on tropical climate condition: A case study in Malaysia," Energy Build., vol. 119, pp. 233-241, 2016.

[7] S. C. Chua, T. H. Oh, and W. W. Goh, "Feed-in tariff outlook in Malaysia," Renew. Sustain. Energy Rev., vol. 15, no. 1, pp. 705-712, 2011.

[8] M. A. Almaktar, H. Y. Mahmoud, E. Y. Daoud, and Z. R. Hasan, "Meteorological Parameters in Malaysia : An Investigation Between Real Measurements and NASA Database," Adv. Electr. Electron. Eng. Sci. J., vol. 1, no. January, pp. 1-7, 2017.

[9] J. Sulaiman, A. Azman, and B. Saboori, "DEVELOPMENT OF SOLAR ENERGY IN SABAH MALAYSIA: THE CASE OF TRUDGILL ' S PERCEPTION," Int. J. Sustain. Energy Environ. Res., vol. 3, no. 2, pp. 90-99, 2014.

[10] M. I. Hlal, V. K. Ramachandaramurthya, and S. Padmanaban, "NSGA-II and MOPSO based optimization for sizing of hybrid PV/wind/battery energy storage system," Int. J. Power Electron. Drive Syst., vol. 10, no. 1, pp. 463-478, 2019.

[11] T. Soubdhan, R. Emilion, and R. Calif, "Classification of daily solar radiation distributions using a mixture of Dirichlet distributions," Sol. Energy, vol. 83, no. 7, pp. 1056-1063, 2009.

[12] L. J. Gray et al., "Solar influences on climate," Rev. Geophys., vol. 48, no. 2009, p. RG4001, 2010.

[13] T. E. Hoff and R. Perez, "Quantifying PV power Output Variability," Sol. Energy, vol. 84, no. 10, pp. 1782-1793, 2010.

[14] A. Mills, M. Ahlstrom, M. Brower, A. Ellis, and R. George, Understanding Variability and Uncertainty of Photovoltaics for Integration with the Electric Power System. 2009.

[15] S. N. Fadilah, N. M. Saad, M. F. Abas, and N. L. Ramli, "Modeling and simulation of UPFC for dynamic voltage control in power system using PSCAD/EMTDC software," ARPN J. Eng. Appl. Sci., vol. 10, no. 21, pp. 9943-9948, 2015.

[16] N. M. Saad, M. Z. Sujod, M. F. Abas, M. H. Sulaiman, and M. I. M. Rashid, "OPTIMAL PLACEMENT AND SIZING OF DISTRIBUTED GENERATION BASED ON MVMO-SH," in 5th IET International Conference on Clean Energy and Technology, CEAT 2018, Kuala Lumpur.

[17] K. Y. Liu, W. Sheng, Y. Liu, X. Meng, and Y. Liu, "Optimal sitting and sizing of DGs in distribution system considering time sequence characteristics of loads and DGs," Int. J. Electr. Power Energy Syst., vol. 69 , pp. 430-440, 2015.

[18] S. Liu, F. Liu, T. Ding, and Z. Bie, "Optimal Allocation of Reactive Power Compensators and Energy Storages in Microgrids Considering Uncertainty of Photovoltaics," Energy Procedia, vol. 103, pp. 165-170, 2016.

[19] P. P. Barker and R. W. De Mello, "Determining the impact of distributed generation on power systems. Part I. Radial distribution systems," Power Eng. Soc. Summer Meet. 2000. IEEE, vol. 3, pp. 1645-1656, 2000.

[20] N. Jaalam, N. A. Rahim, A. H. A. Bakar, C. Tan, and A. M. A. Haidar, "A comprehensive review of synchronization methods for grid-connected converters of renewable energy source," Renew. Sustain. Energy Rev., vol. 59, no. JUNE, pp. 1471-1481, 2016.

[21] Y. M. Atwa, E. F. El-Saadany, M. M. A. Salama, and R. Seethapathy, "Optimal Renewable Resources Mix for Distribution System Energy Loss Minimization,” Power Syst. IEEE Trans., vol. 25, no. 1, pp. 360-370, 2010.

[22] Reuven Y. Rubinstein, Simulation and The Monte Carlo Method, 3rd Editio. Wiley Series in Probability and Mathematical Statistics, 2016.

[23] K. Zou, A. P. Agalgaonkar, K. M. Muttaqi, and S. Perera, "Distribution system planning with incorporating DG reactive capability and system uncertainties," IEEE Trans. Sustain. Energy, vol. 3, no. 1, pp. 112-123, 2012.

[24] A. Ali, M. Nor, and T. Ibrahim, "Sizing and placement of solar photovoltaic plants by using time-series historical weather data," J. Renew. Sustain. Energy, vol. 10, no. 2, pp. 1-17, 2018.

[25] A. Ali, M. Nor, T. Ibrahim, and M. Fakhizan, "Sizing and placement of battery-coupled distributed photovoltaic generations," J. Renew. Sustain. ENERGY, vol. 9, no. 5, pp. 1-18, 2017. 